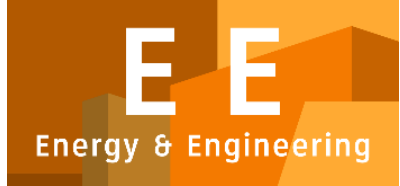

PAPER - OPEN ACCESS

\title{
Analisa Respon Mekanik Speed Bump Paduan Bahan Concrete Foam dan Polymeric Foam Diperkuat Serat Tandan Kelapa Sawit (TKKS) yang Dikenai Beban Impact Jatuh Bebas
}

\author{
Author : Herry Darmadi \\ DOI $\quad: 10.32734 /$ ee.v1i1.120 \\ ISSN :2654-7031 \\ E-ISSN : 2654-704X
}

Volume 1 Issue 1 - 2018 TALENTA Conference Series: Energy and Engineering

\section{(a) $(1) \Theta$}

This work is licensed under a Creative Commons Attribution-NoDerivatives 4.0 International License.

Published under licence by TALENTA Publisher, Universitas Sumatera Utara
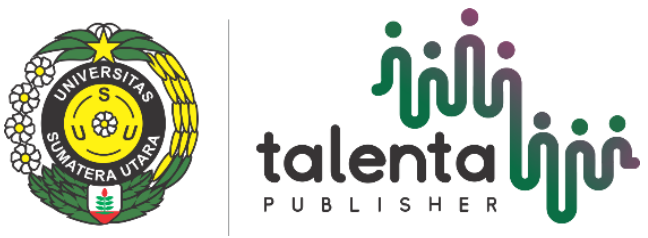


\title{
Analisa Respon Mekanik Speed Bump Paduan Bahan Concrete Foam dan Polymeric Foam Diperkuat Serat Tandan Kelapa Sawit (TKKS) yang Dikenai Beban Impact Jatuh Bebas
}

\author{
Imalsyah Fasi $^{\mathrm{a}}$, Herry Darmadi ${ }^{\mathrm{a}^{*}}$, Bustami Syam ${ }^{\mathrm{a}}$ \\ ${ }^{a}$ Fakultas Teknik, Universitas Sumatera Utara, Medan, 20155 \\ herry.darmadi@gmail.com
}

\begin{abstract}
Abstrak
Tandan Kosong Kelapa Sawit (TKKS) memiliki nilai untuk direkayasa menjadi material alternatif yang dapat dimanfaatkan dengan alasan masih berlimpahnya bahan baku, umur pakai dapat lebih lama, mudah di desain, dapat didaur ulang, bebas korosi, tahan dan mampu menyerap suhu panas, serta ekonomis, seperti untuk pembuatan papan partikel. Tujuan penelitian ini untuk mendapatkan proses pembuatan dan menganalisa respon speed bump terhadap beban impak jatuh bebas. Spesimen yang diuji untuk uji impak jatuh bebasberbentuk speed bump yaitu berdimensi $200 \times 200 \times 150 \mathrm{~mm}$. Pembuatan speed bumper dilakukan dengan cara menggunakan cetakan yang berukuran $400 \times 400 \times 150$ (mm). Hasil uji karakteristik mekanik diperoleh dari Rata-rata tegangan impak datar dengan ketinggin 1 meter adalah 415,2142 N. Rata-rata tegangan impak datar dengan ketinggin 1 meter adalah 724,5164 N. Rata- rata tegangan impak datar dengan ketinggin 1 meter adalah $247,4222 \mathrm{~N}$. Rata-rata tegangan impak datar dengan ketinggin 1 meter adalah $128,075 \mathrm{~N}$.
\end{abstract}

Kata Kunci: Speed bump; kekuatan struktur; ansys 14.5

\section{Pendahuluan}

Sudah banyak penelitian bahan bangunan yang dilakukan untuk mencari bahan bangunan yang kuat, ringan, tahan lama dan ekonomis. Dalam hal ini penggunaan beton dengan berat volume yang lebih ringan dari beton normal akan memberikan keuntungan yang signifikan antara lain: mengurangi luas penampang struktur, mereduksi beban gempa dan pondasi, dan mengurangi dampak lingkungan disekitar proyek. Berat volume beton dapat dikurangi dengan prinsip mengganti material bahan berbutir dengan rongga udara atau material pengisi yang lebih ringan.

Tandan kosong kelapa sawit (TKKS) merupakan limbah yang dihasilkan pabrik pengolahan minyak kelapa sawit. Produksi Indonesia minyak kelapa sawit kasar indonesia mencapai 6 juta ton pertahun, dan secara bersaman dihasilkan pula limbah TKKS dengan potensi sekitar 2,5 juta ton per tahun (Anonim, 1999). Limbah ini biasanya dibakar sehingga dapat mencemari udara. Salah satu usaha dalam mengatasinya adalah dengan memanfaatkan tandan kosong kelapa sawit ini untuk pencampuran bahan concrete foam (confoam) yang dilakukan pencampurannya dengan metode fisika. Confoam dengan massa jenis yang lebih kecil digunakan untuk berbagai produk teknologi, misalnya sebagai bahan panel akustik, bata ringan, dll [2]. Dalam penelitian ini, bahan ini digunakan untuk speed bump (polisi tidur). 


\section{Metode dan Bahan Penelitian}

Penelitian dimulai dengan survei keadaan speed bump yang telah terpasang di berbagai ruas jalan di Kota Medan. Ditemui bahwa masih banyak speed bump yang belum memenuhi standard KM Menhub nomor 3 tahun 1994.

Untuk kebutuhan simulasi diperlukan beberapa parameter, antara lain: sifat mekanik dan fisik material confoam. Untuk itu material confoam disiapkan dan diuji untuk mendapatkan nilai modulus elastisitas (E), massa jenis $(\rho)$, kekuatan tarik $\left(\mathrm{S}_{\mathrm{ut}}\right)$, dan kekuatan tekan $\left(\mathrm{S}_{\mathrm{uc}}\right)$.

Penyelidikan distribusi tegangan pada speed bump dilaksanakan di IC-STAR USU. Adapun software yang digunakan adalah ANSYS Workbench 14.5 dengan basis metode elemen hingga. Langkah simulasi dengan menggunakan program ANSYS dapat dilakukan dalam 3 golongan proses pengerjaan yaitu: Preprocessing, solution, dan post processing. Data-data yang dimasukkan kedalam simulasi diambil dari data-data pengujian eksperimental.

Alat dan bahan penelitian ditunjukkan pada Tabel 1 dan 2.

Tabel. 1. Alat

\begin{tabular}{clc}
\hline No & Nama Alat & Metode Fisika \\
\hline 1 & $\begin{array}{l}\text { Alat uji tekan statik beton menggunakan mesin } \\
\text { Compression Testing Machine buatan Jerman dengan } \\
\text { standar ASTM C-39 dan maksimum kompresi hingga }\end{array}$ & $\checkmark$ \\
& 10.000 Psi & \\
2 & Horizontal shaft mixer & $\checkmark$ \\
3 & Kompressor & $\checkmark$ \\
4 & Foam generator & $\checkmark$ \\
5 & Timbangan digital & $\checkmark$ \\
6 & Mesin penghalus serat & $\checkmark$ \\
7 & Software Auto CAD \& ANSYS & $\checkmark$ \\
8 & Cetakan & $\checkmark$ \\
9 & Gelas ukur & $\checkmark$ \\
\hline
\end{tabular}

Tabel. 2. Bahan

\begin{tabular}{clc}
\hline No & Nama Bahan & Metode Fisika \\
\hline 1 & Pasir & $\checkmark$ \\
2 & Semen & $\checkmark$ \\
3 & Air bersih & $\checkmark$ \\
4 & Deltamix blowing agent & $\checkmark$ \\
5 & Serat TKKS & $\checkmark$ \\
\hline
\end{tabular}

Persiapan serat TKKS diperoleh dari hasil pengolahan tandan kosong kelapa sawit dengan beberapa tahapan proses. Tahapan tersebut adalah:

- Perendaman TKKS dalam air yang mengandung larutan $\mathrm{NaOH} 1 \%$ selama 24 jam.

- Pencucian dengan air bersih.

- Pengeringan dengan cara menjemur serat ini pada sinar matahari selama \pm 3 hari atau dapat juga menggunakan mesin pengering.

- Pencacahan serat menjadi bagian-bagian kecil (5 s.d. $10 \mathrm{~cm})$.

- Penghalusan serat dengan menggunakan mesin penghalus serat 
Proses pembuatan concrete foam dengan metode fisika adalah sebagai berikut :

- Mengayak pasir; untuk mendapatkan ukuran butir yang sama dan memisahkan partikel lain yang tidak dibutuhkan seperti kotoran-kotoran kayu, daun kering, dll.

- Mengayak semen; untuk memisahkan gumpalan-gumpalan semen yang disebabkan oleh kelembaban lingkungan penyimpanan.

- Persiapkan serat TKKS; timbang serat ini sesuai dengan komposisi yang telah ditentukan. Pemilihan serat berbentuk serat panjang antara $0,5-1 \mathrm{~cm}$.

- Hidupkan horizontal shaft mixer

- Masukkan pasir + semen + air ke dalam horizontal shaft mixer sampai pasir, air dan semen tercampur secara merata

- Hidupkan mesin foam generator; gunakan blowing agent dari bahandeltamix foam agent sampai busa terbentuk danpisahkan.

- Campurkan urutan e + serat TKKS; aduk kembali campuran ini dengan menggunakan horizontal shaft mixer sampai merata.

- Masukkan foam/busa yang dibangkitkan oleh foam generator ke dalam campuran pada urutan 7 .

- Setelah pengadukan beberapa menit kemudian, maka hasil akhir adalah foam mortar atau beton berbusa dengan agregat ringan serat TKKS, dan segera mengecor atau menuangkan ke dalam cetakan yang telah disiapkan terlebih dahulu.

\section{Hasil dan Pembahasan}

\subsection{Geometri, dimensi, dan material spped bump}

Desain yang dilakukan adalah berupa struktur yang terdiri dari dua potongan, yaitu A dan B, di mana potongan A berbentuk segi empat dan potongan B berbentuk parabola. Dimensi kedua bentuk speed bump secara detil ditunjukkan pada Gbr. 1, di mana lebarnya $200 \mathrm{~mm}$ dan tinggi dari permukaan jalan $50 \mathrm{~mm}$, panjang speed bump menyesuaikan dengan lebar jalan; dalam simulasi ukuran panjang speed bump dibuat dengan ukuran $400 \mathrm{~mm}$. Geometri dan dimensi speed bump dapat diubah andai kata tidak memenuhi standard kekuatan struktur.

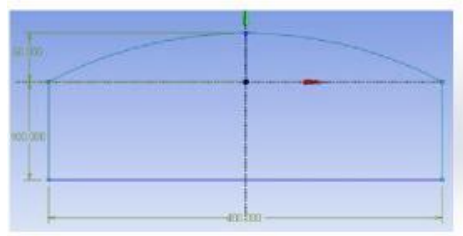

(a) Padat

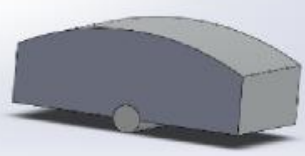

(b) Berongga

Gambar. 1. Geometri dan dimensi desain speed bump berongga
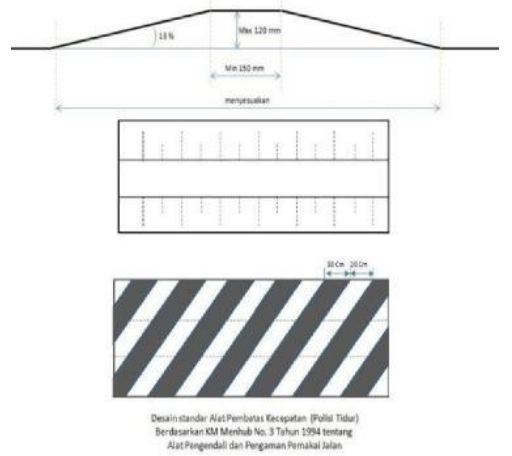
Gambar. 2. Peraturan Kemenhub nomor 31994 2).

Ukuran yang digunakan serta geometri adalah modifikasi dari Peraturan Kemenhub no 3 tahun 1994 (Gambar.

Pada penelitian ini, material speed bump dibuat dari bahan concrete foam, baik untuk geometri Gambar 1 (a) dan (b). Dari hasil pengujian sifat mekanik material yang diperlukan dalam simulasi diperoleh dan dapat ditunjukkan dalam Tabel 3.

Tabel. 3. Sifat mekanik material speed bump ( Laporan penelitian MP3EI )

\begin{tabular}{ccccc}
\hline Type spesimen & Suc(MPa) & Sut, $(\mathrm{MPa})$ & $\rho$ & E (MPa \\
\hline A5 & 2.1 & 0.18 & 0.2 & 10.1
\end{tabular}

\subsection{Pengujian Jatuh Bebas}

Pengujian impak dilakukan dengan metode impak jatuh bebas, dan dengan jumlah sampel 6 buah dengan variasi ketinggian diantaranya: $1 \mathrm{~m}$ dan $3 \mathrm{~m}$, dengan dua jenis posisi Speed Bump. Pertama, posisi Speed Bump tegak lurus (Gambar 3) dan kedua, posisi Speed Bump miring (Gambar 4). Hal ini dilakukan untuk mendapatkan tegangan yang bekerja pada material tersebut sehingga akan diperoleh hasil akhir bahwa material tersebut memiliki kemampuan yang dibutuhkan oleh speed bump. Sehingga pada pemakaian speed bump dapat bekerja secara maksimal.

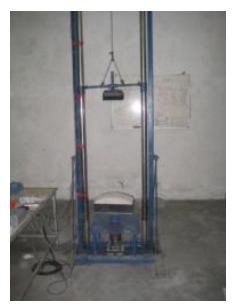

Gambar. 3. Posisi Speed Bump tegak lurus

Grafik gaya impak pada spesimen posisi datar dengan ketinggian 2 meter dan specimen concrete, diperlihatkan seperti pada Gambar 4.

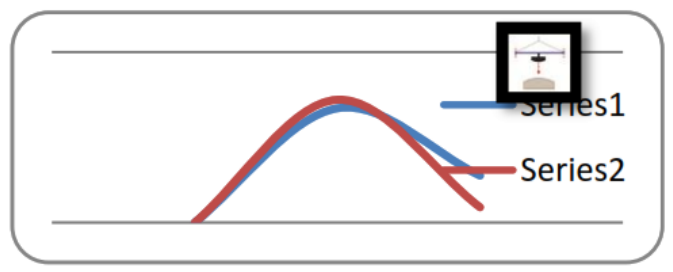

Gambar. 4. Grafik gaya impak pada ketinggian $2 \mathrm{~m}$ posisi speed bump datar dan specimen concrete

Grafik Gaya impak pada spesimen posisi datar dengan ketinggian 2 meter dan specimen rongga 1 inchi, diperlihatkan seperti pada Gambar 5.

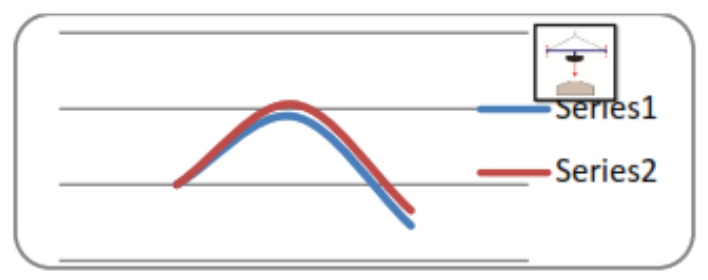

Gambar. 5. Grafik gaya impak.pada ketinggian $2 \mathrm{~m}$ posisi speed bump datar dan specimen rongga 1 inchi 
Grafik Gaya impak pada spesimen posisi miring dengan ketinggian 2 meter dan specimen rongga 2 inchi, diperlihatkan seperti pada

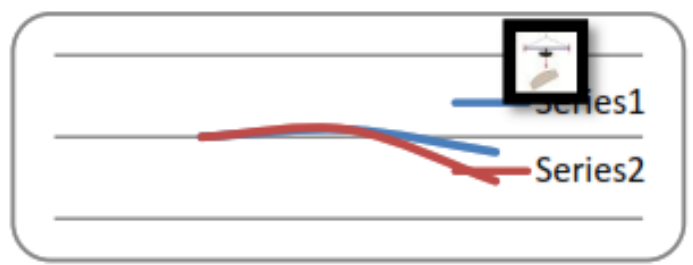
Gambar 6.

Gambar. 6. Grafik gaya impak.pada ketinggian $2 \mathrm{~m}$ posisi speed bump datar dan specimen rongga 2 inchi

Grafik Gaya impak pada spesimen posisi miring dengan ketinggian 3 meter, diperlihatkan seperti pada Gambar 7.

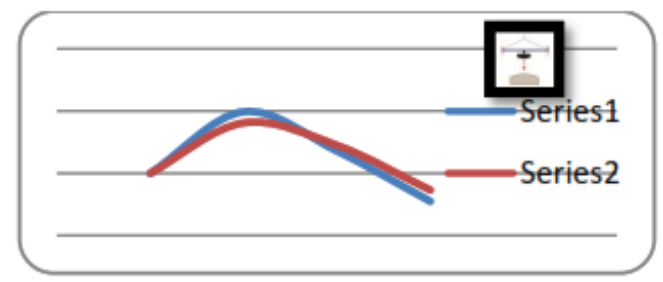

Gambar. 7. Grafik gaya impak.pada ketinggian $2 \mathrm{~m}$ posisi speed bump datar dan specimen rongga 3 inchi

Pada daerah pembebanan, luas daerah pembebanan adalah $0,002 \mathrm{~m}^{2}$ yang merupakan luas penampang, hasil dari perbandingan antara gaya impak dengan luas penampang maka akan dihasilkan tegangan. Sedangkan energi diperoleh dari hasil kali gaya impak dengan ketinggian hasil ini ditabulasikan dalam Tabel 4, 5 dan 6 berikut.

Tabel. 4. Hasil pengujian impak jatuh bebas (gaya impak maksimum).

\begin{tabular}{lccc}
\hline \multicolumn{1}{c}{ Tipe } & $\begin{array}{c}\text { Spesim } \\
\text { en }\end{array}$ & $\begin{array}{c}\text { Ketinggian } \\
(\text { meter })\end{array}$ & $\begin{array}{c}\text { Gaya impak } \\
\max (\mathrm{N})\end{array}$ \\
\hline Concrete & 1 & 2 & 132,398 \\
& 2 & 2 & 142,198 \\
Rongga 1 & 1 & 2 & 44.1 \\
inch & 2 & 2 & 51.94 \\
Rongga 2 & 1 & 2 & 20,58 \\
inch & 2 & 2 & 19,6 \\
Rongga 3 & 1 & 2 & 97,118 \\
inch & 2 & 2 & 88,2 \\
\hline
\end{tabular}

Tabel. 5. Hasil pengujian impak jatuh bebas (Tegangan)

\begin{tabular}{lccl}
\hline \multicolumn{1}{c}{ Tipe } & Spesim en & $\begin{array}{c}\text { Ketinggian } \\
(\text { meter })\end{array}$ & $\begin{array}{c}\text { Tegangan } \\
(\mathrm{MPa})\end{array}$ \\
\hline Concrete & 1 & 2 & 0,04 \\
Rongga 1 & 2 & 2 & 0,04 \\
inch & 1 & 2 & 0,01 \\
Rongga 2 & 1 & 2 & 0,01 \\
inch & 2 & 2 & 0,06 \\
Rongga 3 & 1 & 2 & 0,06 \\
inch & 2 & 2 & 0,03 \\
\hline
\end{tabular}


Tabel. 6. Hasil pengujian impak jatuh bebas (Kondisi spesimen)

\begin{tabular}{lccl}
\hline \multicolumn{1}{c}{ Tipe } & $\begin{array}{c}\text { Spesim } \\
\text { en }\end{array}$ & $\begin{array}{c}\text { Ketinggian } \\
\text { (meter) }\end{array}$ & $\begin{array}{c}\text { Kondisi } \\
\text { spesimen }\end{array}$ \\
\hline Concrete & 1 & 2 & Retak \\
& 2 & 2 & Retak \\
Rongga 1 & 1 & 2 & Retak \\
inch & 2 & 2 & Retak \\
Rongga 2 & 1 & 2 & Retak \\
inch & 2 & 2 & Retak \\
Rongga 3 & 1 & 2 & Retak \\
inch & 2 & 2 & Retak \\
\hline
\end{tabular}

\section{Kesimpulan}

Berdasarkan penelitian dan analisis yang telah dilakukan maka kesimpulan dari hasil penelitian ini yaitu:

- Pada ketinggian $2 \mathrm{~m}$ posisi datar concrete foam ; specimen satu ; F max = 132,398 N, dan Tegangan $=0,044$ MPa. Spesimen dua $\mathrm{F} \max =142,198 \mathrm{~N}$, dan Tegangan $=0,047 \mathrm{Mpa}$ Spesimen tiga $\mathrm{F} \max =131,32 \mathrm{~N}$, Tegangan $=0,043 \mathrm{MPa}$. Pada ketinggian $2 \mathrm{~m}$ corete foam terjadi keretakan.

- Pada ketinggian $2 \mathrm{~m}$ posisi datar rongga 1 inch; specimen satu; $\mathrm{F} \max =44,1 \mathrm{~N}$, dan tegangan =0,014 $\mathrm{MPa}$. Spesimen dua $\mathrm{F} \max =51,94 \mathrm{~N}$, dan Tegangan= 0,017 MPa. Spesimen tiga $\mathrm{F} \max =34,44 \mathrm{~N}$, dan Tegangan= $0,011 \mathrm{MPa}$. Pada ketinggian $2 \mathrm{~m}$ rongga 1 inch terjadi keretakan.

- Pada ketinggian $2 \mathrm{~m}$ posisi datar rongga $2 \mathrm{inch}$; specimen satu; F max = 20,58 N, dan Tegangan 0,06 MPa. Spesimen dua $\mathrm{F} \max =19,6 \mathrm{~N}$, dan Tegangan=0,06 MPa. Spesimen tiga $\mathrm{F} \max =18,6 \mathrm{~N}$, dan Tegangan= 0,06 $\mathrm{MPa}$. Pada ketinggian $2 \mathrm{~m}$ rongga 2 inch terjadi keretakan.

- Pada ketinggian $2 \mathrm{~m}$ posisi datar rongga 3 inch; specimen satu; $\mathrm{F}$ max=97,118 N, dan Tegangan=0,032 $\mathrm{MPa}$. Spesimen dua $\mathrm{F} \max =88,2 \mathrm{~N}$, dan Tegangan= 0,029 MPa, Spesimen tiga $\mathrm{F} \max =79,478 \mathrm{~N}$, dan Tegangan= 0,026 $\mathrm{MPa}$. Pada ketinggian $2 \mathrm{~m}$ rongga 3 inch terjadi keretakan.

\section{Referensi}

[1] http://id.wikipedia.org/wiki/Polisi tidur

[2] Syam, B., Samsul R, Basuki WD, dan Zulfikar, Laporan Riset MP3EI 2013.

[3] Zulfadhli dan B. Syam, Pengembangan Model dan Analisa Respon Parking Bumper dari Bahan Polymeric Foam Diperkuat Serat Tandan Kosong Kelapa Sawit (TKKS) terhadap Beban Impak Jatuh Bebas, Jurnal e-Dinamis, Volume. 6, No.2 September 2013, pp. $108-116$.

[4] Irwan, A, Mahadi, R.D.W. Lubis, dan B. Syam, Pengembangan Material Komposit Busa Polimer Menggunakan Serat TKKS Sebagai Penguat, Prosiding Seminar Nasional Rekayasa dan Teknologi (SNRT), 4 Des. 2013, Reuleut Lhokseumawe, pp. 367-371.

[5] Kaban, N.L dan B. Syam, Pengaruh Pembebanan Impak Jatuh Bebas pada Concrete Foam dengan Variasi Komposisi Poliuretan yang Diperkuat Serat TKKS, Jurnal e-Dinamis, Volume. 10, No.2 September 2014, pp. 135-142.

[6] Maraghi, M., N. Fitriadi, Y. Siahaan, Abdurrahman, Irwansyah, dan B. Syam, Pembuatan dan Analisis Struktur Speed Bump Bahan Komposit Busa Beton (Concrete Foam), Prosiding Seminar Nasional Rekayasa dan Teknologi (SNRT), 4 Des. 2013, Reuleut Lhokseumawe, pp. 343-351. 